\title{
IgE concentrations in allergic asthma in children
}

\author{
J. HAVNEN, P. A. AMLIE, M. HVATUM, S. OSEID, T. VEGGAN, and K. AAS \\ From the Children's Asthma and Allergy Institute; and the Paediatric Research Institute, Rikshospitalet, University \\ Hospital, Oslo, Norway
}

\begin{abstract}
Havnen, J., Amlie, P. A., Hvatum, M., Oseid, S., Veggan, T., and Aas, K. (1973). Archives of Disease in Childhood, 48, 850. IgE concentrations in allergic asthma in children. Serum concentrations of immunoglobulin $\mathrm{E}$ (IgE) were determined in 197 children, aged 2 to 16 years, with bronchial asthma. $47 \%$ of the children had raised concentrations of IgE in serum. Patients hypersensitive to two or more allergens showed a higher incidence of raised IgE in serum $(52 \%)$ than those reacting to only one allergen ( $23 \%$ ), whereas only 1 of the 10 children in whom allergy investigation proved negative had raised serum IgE. In children where bronchial asthma was the only atopic disease, the incidence of raised serum IgE was low (14\%), whereas high incidences $(58-84 \%$ ) were found when atopic dermatitis, urticaria, and gastrointestinal allergy occurred in addition to bronchial asthma. Patients with food allergy had a higher incidence of raised serum IgE than the total group of patients with allergic bronchial asthma. No significant difference in serum IgE concentrations was found in children subjected to hyposensitization therapy as compared with those who had not received such treatment.

It is concluded that serum IgE determination is a valuable diagnostic tool in distinguishing between allergic and nonallergic asthma in selected cases, when it is used as a supplement to a thorough allergy investigation.
\end{abstract}

There is now ample evidence that the reaginic antibody responsible for the immediate hypersensitivity type of human allergy belongs to immunoglobulin E (IgE) in most, if not all, instances (Aas and Johansson, 1971; Bennich and Johansson, 1971; Berg and Johansson, 1969; Berg, Bennich, and Johansson, 1971; Ishizaka, Ishizaka, and Hornbrook, 1966; Johansson and Bennich, 1967; Stanworth, 1971). Raised serum concentration of IgE has been reported in a proportion of patients with allergic asthma, hay fever, atopic dermatitis, and urticaria (Berg and Johansson, 1969; Gleich, Averbeck, and Swedlund, 1970; Johansson and Bennich, 1967; Juhlin et al., 1969; Kumar et al., 1971; Rowe and Wood, 1970).

The aim of this study was to determine to what extent raised serum IgE concentrations are found in allergic bronchial asthma. Serum IgE concentrations were determined in 197 children with bronchial asthma, 187 of whom were shown to suffer from bronchial allergy.

IgE determinations were made by means of the

Received 25 April 1973.
Phadebas $\left({ }^{\mathrm{R}}\right)$ IgE Test, now commercially available.* The method represents a modification of the radioimmunosorbent technique developed by Wide and Porath (1966).

\section{Materials and methods}

Among children aged 2 to 16 years referred for bronchial asthma, 197 (68 girls, 129 boys) were selected. All patients had been subjected to extensive allergy investigations using history, skin tests, and bronchial provocation tests with methods and material described by Aas $(1969,1970)$. As far as gastrointestinal allergy was concerned, only obvious and immediate reactions to food items on repeated occasions were considered. A total of 187 patients were shown to suffer from bronchial allergy. Most of them were allergic to two or more allergens, and many also suffered from atopic dermatitis, allergic rhinitis, and other ailments thought to be caused by reaginic allergy. 87 patients had received hyposensitization to one or more allergens. 9 patients had been treated with corticosteroids for one year or more with daily maintenance doses of prednisone 2.5 to 10 mg. In 10 asthmatic children no causative allergens

^The Phadebas(R) IgE Test was delivered by Pharmacia AB. Uppsala, Sweden. 
could be shown and these patients were included for comparison. 16 of the allergic patients included in this study had also taken part in a previous study of specific reaginic antibodies in serum (Aas and Johansson, 1971). These serum samples were shown to contain high amounts of specific reaginic antibody of the $\mathrm{IgE}$ class (Foucard, Aas, and Johansson, 1973).

Serum was collected at random as far as the season for allergen exposure was concerned. In 10 children serum was collected at different intervals during 1 to 8 years. Samples collected during or shortly after rush-hyposensitization were not accepted in this study.

The Phadebas $\left({ }^{\mathrm{R}}\right)$ IgE Test kits contained the following lyophilized substances. (1) Anti-IgE antibodies covalently bound to Sephadex $\left({ }^{R}\right)$ particles as the solid phase. (2) A known amount of IgE for preparation of serial dilutions for a standard curve. (3) ${ }^{125} \mathrm{I}$-labelled IgE. (4) Buffer substance, for $100 \mathrm{ml}$ buffer with $p \mathrm{H}$ $7 \cdot 4$.

We found the preparation of up to 275 test tubes, or 5 kits, to be an appropriate daily work load for one technician with our equipment. With duplicates for each sample and one standard curve for each kit, the material in one kit was sufficient for 15 sera. With later use of one standard curve for 144 tubes (one full centrifuge) for 5 kits of the same lot, 20 to 23 sera per kit could be analysed. For completion of the analyses of 275 samples, approximately 6 and 4 hours of work was required on two successive days.

Fig. 1 shows a typical diagram where counts per

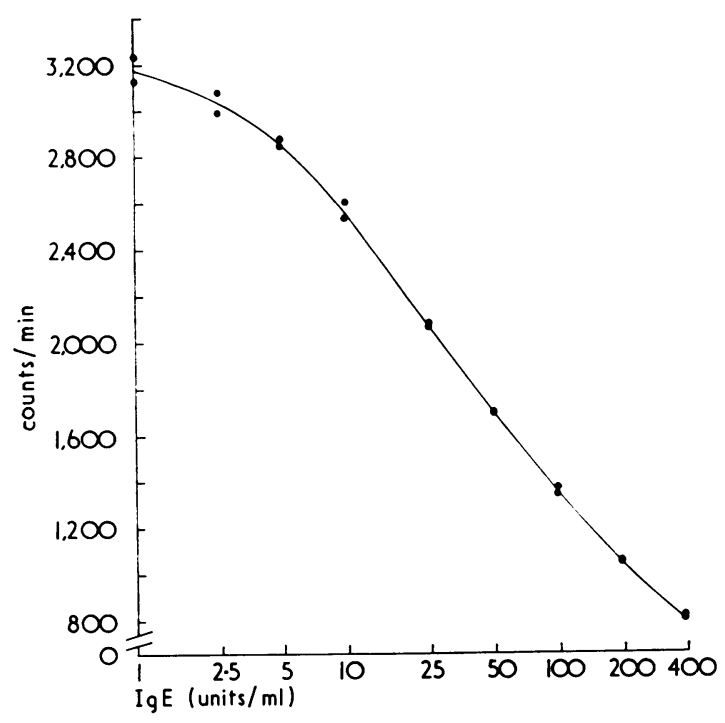

FIG. 1.-A typical standard curve where fixed amounts of ${ }^{125} \mathrm{Ig} E$ and unlabelled IgE from dilutions of a standard $\mathrm{IgE}$ (or a serum sample) compete for the antigen combining sites of the anti-IgE, coupled to the Sephadex particles. The count rates are reduced when the amount of unlabelled $\operatorname{IgE}$ is increased. minute were plotted as a function of serial dilutions of IgE units $/ \mathrm{ml}$. We found it most practical to base estimations of IgE directly on the counts observed and not in percentage of the activity bound by a buffer control, as prescribed in the manufacturer's directions for use. This saved calculation work and the results were not dependent on a very accurate estimation of the buffer control. The most reliable readings were between 5 and $100 \mathrm{IgE}$ units/ml in the diluted sample.

In 3 weeks 19 sera were analysed with kits of the same production 3 times. The range of mean deviation of the three analyses was 0.8 to $30.6 \%$ (mean $10.5 \%$ ). The variation observed did not seem to depend on the age of the kits in spite of a fall in the binding capacity from 13.2 to $8 \cdot 2 \%$. Binding capacity is a measure of the functional condition of the kits indicating the activity bound in the buffer control, expressed as percentage of the activity added. The lowest functional limit of this capacity was $10 \%$, according to the manufacturer.

Normal IgE values. The IgE values measured were compared with the values of 113 normal, nonallergic individuals aged 2 to 16 years, reported by S. G. O. Johansson and T. Berg (personal communication, 1972) (Table I). Values above 200 units $/ \mathrm{ml}$ for children

\section{TABLE I}

Serum IgE concentrations in units/ml for nonallergic children ${ }^{\star}$

\begin{tabular}{c|c|c}
\hline $\begin{array}{c}\text { Age } \\
(\mathrm{yr})\end{array}$ & Mean & 2 SD confidence limits \\
\hline $2-5$ & $65 \cdot 0$ & \\
$5-10$ & $102 \cdot 0$ & $21 \cdot 3-198$ \\
$10-20$ & $85 \cdot 9$ & $17 \cdot 6-594$ \\
& $12 \cdot 0-616$ \\
\hline
\end{tabular}

*S.G.O. Johansson and T. Berg (personal communication, 1972). Note: 2 SD confidence limits are calculated on the logarithmic IgE values.

2 to 5 years and above 600 units $/ \mathrm{ml}$ for older children were considered to be high. These values were lower than those originally reported (Berg and Johansson, 1969). Preliminary investigations have shown that results obtained with the Phadebas IgE Test are comparable to those obtained with the radioimmunosorbent technique used by S. G. O. Johansson and T. Berg (personal communication, 1972). Values for children 2 to 6 years and 6 to 15 years were considered separately to facilitate comparison with other studies (Kumar et al., 1971).

\section{Results}

In 166 allergic children aged 6 to 16 years, serum IgE concentrations were scattered over a wide range, with a few values as high as 3000 to 8000 units/ml (Fig. 2). A similar variation was found in the 2- to 6-year age group.

Raised serum IgE values were most frequently 


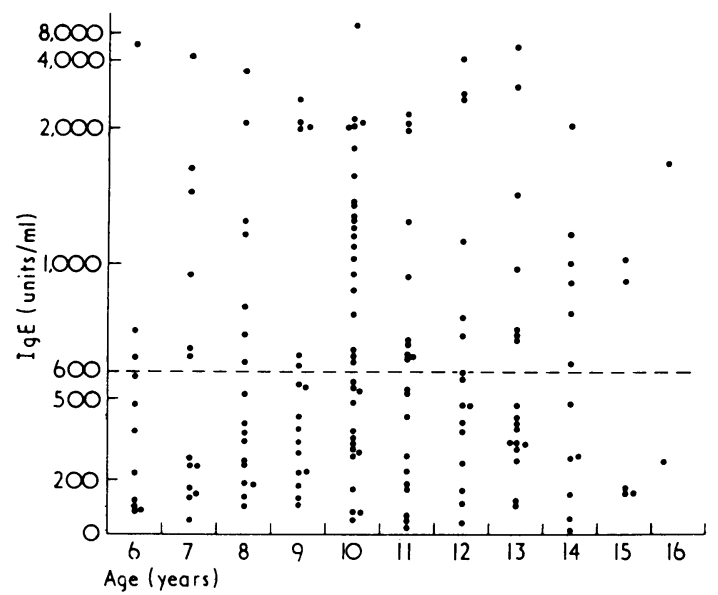

FIG. 2.-Serum IgE concentrations in 166 children aged 6 to 16 years with allergic asthma. Values below 600 units/ml are considered to be within the normal range.

found in children with hypersensitivity to two or more allergens $(52 \%)$, whereas children reacting to only one allergen showed a lower incidence $(23 \%)$.
A raised IgE level was found in only 1 of the 10 children in whom allergy investigation proved negative (Table II).

Factors of importance for the serum IgE levels were the occurrence of other immediate type 'atopic' diseases in addition to bronchial asthma (Table III). The incidence in cases of asthma alone was low $(14 \%)$. The highest incidences were found when $c$ asthma was combined with atopic dermatitis, $\overrightarrow{0}$ urticaria, and/or gastrointestinal allergy. Children with allergy to food items more often showed raised serum IgE levels than those allergic to house dust and moulds (Table IV). The former type of $\cong$ patient was usually allergic to a higher number of $\vec{\infty}$ allergens than the latter type. Among 87 patients aged 6 to 16 years, previously hyposensitized to one or several allergen extracts, 42 patients $(47 \%)$ showed raised serum IgE levels. Among 79 patients not previously hyposensitized, $34(43 \%)$ showed raised serum IgE values. 9 of the allergic children had been treated with corticosteroids for more than 1 year. 3 of them showed increased serum IgE levels. These patients were allergic to several substances with various clinical manifestations of their allergies.

TABLE II

Incidence of raised serum IgE concentrations in asthmatic children aged 2 to 16 years

\begin{tabular}{l|c|c|c|c|}
\hline \multicolumn{1}{c|}{ Result of allergy investigation } & No. of children & $\begin{array}{c}\text { No. of children } \\
\text { with raised serum IgE }\end{array}$ & $\begin{array}{c}\text { Incidence of raised } \\
\text { serum IgE (\%) }\end{array}$ \\
\hline $\begin{array}{l}\text { Children with hypersensitivity to } 2 \text { or more } \\
\text { allergens }\end{array}$ & 170 & 88 \\
$\begin{array}{l}\text { Children with hypersensitivity to 1 allergen } \\
\text { Children in whom allergy investigation } \\
\text { proved negative }\end{array}$ & 17 & 4 & 10 \\
\hline Total no. investigated & 197 & 93 \\
\hline
\end{tabular}

TABLE III

Incidence of raised serum IgE concentrations in allergic asthmatic children aged 2 to 16 years with different combinations of allergic diseases

\begin{tabular}{|c|c|c|c|}
\hline Diagnosis & $\begin{array}{l}\text { No. of children } \\
\text { in each group }\end{array}$ & $\begin{array}{l}\text { No. of children } \\
\text { with raised serum IgE }\end{array}$ & $\begin{array}{l}\text { Incidence of raised } \\
\text { serum } \operatorname{IgE}(\%)\end{array}$ \\
\hline $\begin{array}{l}\text { Asthma only } \\
\text { Asthma + rhinoconjunctivitis only } \\
\text { Asthma + atopic dermatitis } \pm \text { other } \\
\text { hypersensitivity diseases } \\
\text { Asthma + urticaria } \pm \text { other hypersensitivity } \\
\text { diseases } \\
\text { Asthma + urticaria + atopic dermatitis } \pm \text { other } \\
\text { hypersensitivity diseases } \\
\text { Asthma + gastrointestinal allergy } \pm \text { other } \\
\text { hypersensitivity diseases } \\
\text { Asthma + gastrointestinal allergy } \pm \text { atopic } \\
\text { dermatitis } \pm \text { other hypersensitivity diseases }\end{array}$ & $\begin{array}{l}22 \\
33 \\
70 \\
75 \\
24 \\
13 \\
2\end{array}$ & $\begin{array}{r}3 \\
13 \\
41 \\
46 \\
12 \\
11 \\
0\end{array}$ & $\begin{array}{l}14 \\
39 \\
58 \\
61 \\
50 \\
84\end{array}$ \\
\hline
\end{tabular}


TABLE IV

Incidence of raised serum IgE concentrations in asthmatic children aged 2 to 16 years related to allergy to some main groups of allergens

\begin{tabular}{l|c|c|c}
\hline Allergy to & $\begin{array}{c}\text { No. of } \\
\text { children in } \\
\text { each group }\end{array}$ & $\begin{array}{c}\text { No. of } \\
\text { children with } \\
\text { raised serum } \\
\text { IgE }\end{array}$ & $\begin{array}{c}\text { Incidence of } \\
\text { raised serum } \\
\text { IgE (\%) }\end{array}$ \\
\hline Food & 89 & 59 & 67 \\
Animal danders & 106 & 65 & 61 \\
Pollen & 111 & 67 & 60 \\
House dust & 153 & 79 & 52 \\
Moulds & 96 & 49 & 51 \\
\hline
\end{tabular}

Forty-three patients aged 2 to 16 years showed serum IgE values above 1000 units $/ \mathrm{ml}$. These children presented many of the features already mentioned that are associated with high IgE levels, such as several 'atopic' diseases including atopic dermatitis, and also allergies to a wide variety of substances including food items. Their clinical picture was further characterized by early onset of the allergy and severe reactions to minor allergen exposure. In 5 of the 10 children whose sera were collected at different time intervals, both normal and raised IgE values were found. 4 of the 16 children, shown earlier by radio-allergosorbent test to have high levels of specific IgE antibodies in the sera (Aas and Johansson, 1971; Foucard et al., 1973), belonged to the group of allergic children with normal total IgE values.

\section{Discussion}

The IgE test kits have proved to be convenient and sufficiently reliable for estimation of total values of $\mathrm{IgE}$ in solution. Using the equipment described in the present report, analysis of 116 to 120 sera using 5 kits is an appropriate amount of work for 2 days for one technician.

Concentrations of serum IgE may also be determined by other methods (Ishizaka et al., 1970; Rowe, 1969), but the radioimmunosorbent test appears to be the most practical for large-scale determinations, and is also the most sensitive (Wide, 1971). The values obtained by radioimmunodiffusion and by the radioimmunosorbent test appear to correlate well. However, comparison of results from different investigations is likely to be confused by the use of different standards. Initially, IgE values were expressed in ng. It was later suggested that the values should be expressed in units, and a reference serum was prepared by WHO (IgE Reference Standard, 68/341) (Rowe et al., 1970). It was assumed that 1 unit IgE corres- ponded to $1.0 \mathrm{ng}$ immunoglobulin. However, at present it is expected that 1 unit corresponds to approximately $2 \cdot 4 \mathrm{ng}$ IgE (Bazaral and Hamburger, 1972). This change of standard also affects the normal value stated for serum IgE. The IgE standard in the Phadebas IgE Test is calibrated against the Standard 68/341.

Various studies have shown mean values of serum IgE concentrations in nonallergic individuals from 80 units $/ \mathrm{ml}$ to $330 \mathrm{ng} / \mathrm{ml}$ (Berg and Johansson, 1969; Spitz et al., 1972; Gleich, Averbeck, and Swedlund, 1971; Bazaral, Orgel, and Hamburger, 1971; Virchow, Møller, and Debelic, 1972). The variation in mean values may be partly due to the different techniques used, partly to differences in the populations studied. The materials have been rather limited and extended studies of nonallergic individuals are warranted. One difficulty encountered in establishing normal levels is to exclude all individuals with conditions known to be associated with raised serum IgE.

With the criteria used in the present study, a raised serum IgE concentration was found in $47 \%$ of the children with allergic asthma, as compared to $37 \%$ reported by Kumar et al. (1971). Provided the relation between units and $\mathrm{ng}$ in the standard serum used by Kumar et al. was similar to that used in our study, these investigations are comparable. Our findings are also fairly well correlated to the results of Berg and Johansson (1969), Juhlin et al. (1969), and Gleich et al. (1970). Henderson et al. (1971), using less sensitive tests for serum IgE determinations, found raised serum IgE levels in $76 \%$ of patients with allergic asthma and in $62 \%$ of patients with allergic rhinitis. Wood and Oliver (1972) used a modified single radial immunodiffusion technique with a lower limit of sensitivity of 900 units $/ \mathrm{ml}$. They found IgE concentrations above 1000 units $/ \mathrm{ml}$ in $49 \%$ of 237 children with asthma irrespective of aetiology.

In the present study high serum IgE values were found especially when the asthmatic patient also suffered from other 'atopic' diseases such as atopic dermatitis, allergic rhinitis, etc. Of particular interest is the high incidence of raised serum $\operatorname{IgE}$ in asthmatic children who also suffered from urticaria and gastrointestinal allergy. However, many of these patients also had atopic dermatitis. The high incidence of raised serum IgE concentrations in patients with food allergy may have several explanations. These patients as a group are allergic to a higher number of substances than those allergic to common inhalation allergens. The excessive exposure to allergens in many cases of food allergy, as well as the site of introduction of allergens, may 
also be of importance for the immune response and the concentration of circulating specific reagins. Whether certain food allergens as such are particularly prone to stimulate IgE production should be further investigated.

Approximately $50 \%$ of the patients with proven bronchial allergy showed normal concentrations of serum IgE. This group also included some of the patients where high reaginic activity in serum had been shown by other methods (Aas and Johansson, 1971; Foucard et al., 1973). A normal level of total IgE in serum may conceal even high amounts of circulating, biologically active, specific reagins. The immediate hypersensitivity reaction in a given organ is also primarily dependent on the concentration of the tissue-bound IgE and not on the amount of the circulating IgE (Aas, 1972).

Since variations between normal and raised IgE in the same individual may occur, repeated serum samples should be examined when reaginic allergy of clinical importance is suspected. Raised values of $\mathrm{IgE}$ in serum are most likely to be obtained if serum is collected during, or preferably shortly after, allergen exposure.

In asthmatic patients where no actual allergens have been found by common diagnostic procedures, various incidences of raised serum $\mathrm{IgE}$ concentrations have been reported (Berg and Johansson, 1969; Henderson et al., 1971; Kumar et al., 1971). Henderson et al. (1971) found an incidence of $21 \%$ in their patients with intrinsic asthma, and in the present study 1 of the 10 children with negative allergy investigation showed raised levels of serum IgE. Such patients may suffer from undiagnosed allergies. The practical consequences of a high level of serum IgE in these patients should be an intensified search for exogenous allergies.

It is our opinion that determination of serum $\operatorname{IgE}$ in asthmatic children is a valuable diagnostic tool in distinguishing between allergic and nonallergic asthma in selected cases. However, it should be emphasized that IgE determinations represent only a supplement to a thorough allergy investigation. This investigation should include a detailed history, particularly with respect to allergen exposure and to the presence of other possible immediate hypersensitivity diseases, as well as skin tests, challenges in appropriate tissues, and examinations for pathological eosinophilia in blood and mucous membrane secretions.

\section{REFBRENCES}

Aas, K. (1969). Allergic asthma in childhood. Archives of Disease in Childhood, 44, 1.

Aas, K. (1970). Bronchial provocation tests in asthma. Archives of Disease in Childhood, 45, 221.
Aas, K. (1972). The Biochemical and Immunological Basis of Bronchial Asthma, p. 80. Thomas, Springfield, Illinois.

Aas, K., and Johansson, S. G. O. (1971). The radioallergo-sorbent test (RAST) in the in vitro diagnosis of multiple reaginic allergy. A comparison of diagnostic approaches. Fournal of Allergy and Clinical Immunology, 48, 134.

Bazaral, M., and Hamburger, R. N. (1972). Standardization and stability of immunoglobulin E (IgE). Fournal of Allergy and Clinical Immunology, 49, 189.

Bazaral, M., Orgel, H. A., and Hamburger, R. N. (1971). IgE levels in normal infants and mothers and an inheritance hypothesis. Fournal of Immunology, 107, 794.

Bennich, H., and Johansson, S. G. O. (1971). Structure and biological function of human immunoglobulin E. Advances in Immunology, 13, 1.

Berg, T., Bennich, H., and Johansson, S. G. O. (1971). In vitro diagnosis of atopic allergy. I. A comparison between provocation tests and radioallergosorbent test (R.A.S.T.). International Archives of Allergy and Applied Immunology, 40, 770.

Berg, T., and Johansson, S. G. O. (1969). IgE concentrations in children with atopic diseases. International Archives of Allergy and Applied Immunology. 36, 219.

Foucard, T., Aas, K., and Johansson, S. G. O. (1973). Concentrations of IgE-antibodies, P.K.-titers and chopped lung titers in sera from children with hypersensitivity to cod. Fournal of Allergy and Clinical Immunology, 51, 39.

Gleich, G. J., Averbeck, A. M., and Swedlund, H. A. (1970). Concentration of $\mathrm{IgE}$ in serum of normal and allergic individuals. Fournal of Allergy, 45, 108.

Gleich, G. J., Averbeck, A. K., and Swedlund, H. A. (1971). Measurement of $\mathrm{IgE}$ in normal and allergic serum by radioimmunoassay. Fournal of Laboratory and Clinical Medicine, 77, 690.

Henderson, L. L., Swedlund, H. A., Van Dellen, R. G., Marcoux, J. P., Carryer, H. M., Peters, G. A., and Gleich, G. J. (1971) Evaluation of IgE tests in an allergy practice. fournal of Allergy and Clinical Immunology, 48, 361.

Ishizaka, K., Ishizaka, T., and Hornbrook, M. M. (1966). Physicochemical properties of human reaginic antibody. IV. Presence of a unique immunoglobulin as a carrier of reaginic activity. Fournal of Immunology, 97, 75.

Ishizaka, T., Ishizaka, K., Orange, R. P., and Austen, K. F. (1970) The capacity of human immunoglobulin $\mathrm{E}$ to mediate the release of histamine and slow reacting substance of anaphylaxis (SRS-A) from monkey lung. Fournal of Immunology, 104, 335.

Johansson, S. G. O., and Bennich, H. (1967). Studies on a new class of human immunoglobulins. In Gamma Globulins, p. 193. Nobel Symposium 3. Ed. by J. Killander. Almqvist and Wiksell, Stockholm.

Juhlin, L., Johansson, S. G. O., Bennich, H., Høgman, C., and Thyresson, N. (1969). Immunoglobulin $\mathbf{E}$ in dermatoses. Levels in atopic dermatitis and urticaria. Archives of Dermatology, 100, 12.

Kumar, L., Newcomb, R. W., Ishizaka, R., Middleton, E., Jr., and Hornbrook, M. M. (1971). IgE levels in sera of children with asthma. Pediatrics, 47, 848.

Rowe, D. S. (1969). Radioactive single radial diffusion. A method for increasing the sensitivity of immunochemical quantification of proteins in agar gel. Bulletin of the World Health Organization, 40, 613.

Rowe, D. S., Tackett, L., Bennich, H., Ishizaka, K., Johansson, S. G. O., and Anderson, S. G. (1970). A research standard for human serum immunoglobulin E. Bulletin of the World Health Organization, 43, 609.

Rowe, D. S., and Wood, C. B. S. (1970). The measurement of serum immunoglobulin $E$ levels in healthy adults and children and in children with allergic asthma. International Archives of Allergy and Applied Immunology, 39, 1.

Spitz, E., Gelfand, E. W., Sheffer, A. L., and Austen, K. F. (1972) Serum IgE in clinical immunology and allergy. Fournal of Allergy and Clinical Immunology, 49, 337.

Stanworth, D. R. (1971). Immunglobulin E (reagin) and allergy. Nature, 233, 310

Virchow, C., Møller, E., and Debelic, M. (1972). Immunoglobulin E bei Asthma bronchiale allergicum. Deutsche Medizinische Wochenschrift, 97, 1024. 
Wide, L. (1971). Solid phase antigen-antibody systems. In Radioimmunoassay Methods, p. 405 . Ed. by K. E. Kirkham and W. M. Hunter. Churchill Livingstone, Edinburgh and London.

Wide, L., and Porath, J. (1966). Radioimmunoassays of proteins with use of Sephadex-coupled antibodies. Biochimica et Biophysica Acta, 130, 257.

Wood, C. B. S., and Oliver, J. (1972). Serum IgE in asthmatic children. Relation to age, sex, eczema, and skin sensitivity tests. Archives of Disease in Childhood, 47, 890.

Correspondence to Dr. Jakob Havnen, Children's Asthma and Allergy Institute, Ullveien 14, Voksenkollen, Oslo 3, Norway. 